\title{
Información
}

\section{Acerca de AURA}

El 22 de octubre de 2015 se constituyó la Asociación Uruguaya de Revistas Académicas (AURA).

El acto inaugural, se realizó en la Sala Maestro Julio Castro de la Biblioteca Nacional, con la presencia de más de 60 socios fundadores.

Se destacan entre sus objetivos:

1) Promover la universalización de la producción científica y académica en todas las aéreas del conocimiento;

2) Contribuir a la difusión de las publicaciones periódicas nacionales arbitradas;

3) Promover la profesionalización de la actividad editorial de sus asociados;

4) Velar por la observancia de los principios y reglas éticos relativos a la actividad editorial de sus asociados;

5) Impulsar el análisis crítico en la adopción de estándares internacionales de calidad editorial;

6) Fomentar la coordinación y cooperación entre las revistas nacionales;

7) Fortalecer la comunidad dinámica de editores y gestores de publicaciones arbitradas del país; 
8) Impulsar el diálogo entre los autores, y entre éstos y el público;

9) Establecer y mantener vínculos, colaboración y convenios con revistas, organismos y entidades nacionales y extranjeras.

Celebramos el nuevo impulso que significa este hito en el proceso de desarrollo de las publicaciones académicas de nuestro país.

La integración de la primera Comisión Directiva de la Asociación es la siguiente:

Presidente: Lilián Daset

Vicepresidente: Cecilia Valenzuela

Secretario: Sebastián Griscti

Pro-secretaria: Gabriela Cabrera

Tesorera: Teresa Morelli

\section{Comisión Fiscal:}

Laura Machado

Fernanda Barboza

Luis María Delio

\section{Comisión Electoral:}

Dardo Bardier

Carina Patrón

Héctor Cabo

La labor continúa ahora desde la sede de AURA en la Biblioteca Nacional.

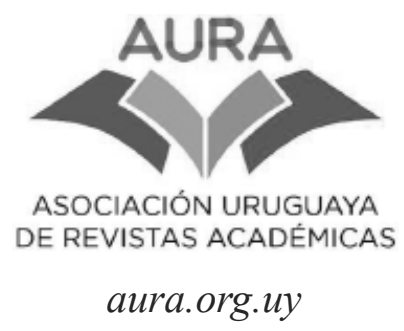

